\title{
Formability of Medium Mn Steel Welded Joints
}

\author{
Yang Cao ${ }^{1,2, *}$, Bo Wang ${ }^{3}$, Lin Zhao ${ }^{2}$, Yun Peng ${ }^{2}$, Minlin Zhong ${ }^{1}$, Hong Zuo ${ }^{3}$ and \\ Zhiling Tian ${ }^{2}$ \\ 1 School of Material Science and Engineering, Tsinghua University, Beijing 100084, China; \\ zhml@tsinghua.edu.cn \\ 2 Central Iron and Steel Research Institute, Beijing 100081, China; hhnds@aliyun.com (L.Z.); \\ yunpeng21@139.com (Y.P.); tianzhl@cisri.com.cn (Z.T.) \\ 3 State Key Laboratory for Strength and Vibration of Mechanical Structures, School of Aerospace, \\ Xi'an Jiaotong University, Xi'an 710049, China; wangbochina@stu.xjtu.edu.cn (B.W.); \\ zuohong@mail.xjtu.edu.cn (H.Z.) \\ * Correspondence: caoyang0531@163.com; Tel.: +86-153-1142-6310
}

Received: 24 April 2020; Accepted: 25 May 2020; Published: 27 May 2020

check for updates

\begin{abstract}
In this study, a new-generation high-strength and high-ductility medium Mn steel (0.1C-5Mn-Fe) for the automotive industry was joined by the fiber laser and gas tungsten arc welding (GTAW) methods. Formability testing of the welded joints was done by the Erichsen cupping test and finite element (FE) analysis. The results showed that the formability of medium Mn steel welded joints was sensitive to the welding parameters and inferior to that of the base metal (BM). The hardening zone (HZ) was formed in the welded joint, which was composed of the fusion zone and two symmetrical parts of the heat-affected zone. The width of the HZ was one of the primary factors affecting the formability of the welded joints, while the tensile strength and ductility of the HZ were secondary factors. FE simulation of the Erichsen cupping test results indicated that the forming strain of the welded joint with narrow $\mathrm{HZ}$ concentrated on the BM, while the forming strain of the welded joint with wide $\mathrm{HZ}$ concentrated on the $\mathrm{HZ}$. The $\mathrm{HZ}$ strain reached the deformation limit first due to its weak ductility; therefore, the welded joint with wide HZ had the worst formability. It was also observed that adopting high-velocity and high-laser power welding could greatly improve the formability of the welded joint as a result of reducing the width of the HZ.
\end{abstract}

Keywords: medium Mn steel; formability; laser welding; welded joints; mechanical properties

\section{Introduction}

In recent years, advanced high-strength steels (AHSSs) are being developed successfully because they can meet the cost saving and weight reduction requirements of manufacturers for automobile bodies. Medium Mn steel, one of the most promising third-generation automobile steels, is gaining increasing attention due to its excellent combination of strength and ductility [1-3]. Welding and joining are indispensable technologies for the automotive manufacturing industry [4-6]. Due to the high quality, high precision, good flexibility, low distortion, and narrow heat-affected zone (HAZ) and fusion zone (FZ), laser welding is widely used in the automotive industry.

Tailor welded blanks (TWBs) are fabricated by laser welding two or more steel sheets with different or similar strength and/or thickness together in a single seam and then stamping the TWBs into complex shapes [7]. The formability of TWBs is one of the most important mechanical properties in the automotive industry, which is influenced by many factors, such as experimental and material processing factors [7-10]. The formability of TWBs can be analyzed by the Erichsen cupping test and limiting dome height test $[11,12]$. However, due to the difference in mechanical properties between the welded joint and the base metal (BM), the formability of the welded joint is usually weaker than 
that of the BM [13-15]. Many studies have indicated that the formability of dual-phase (DP) steels is significantly deteriorated after laser welding due to the formation of a softened zone in the HAZ tempering of preexisting martensite $[8,13,16]$. However, the formability can be improved by local cooling of the HAZ of DP steel [17]. It has been reported that an increase in carbon equivalent (CE) from 0.002 to 0.41 in steel sheets decreases the Erichsen cup height of laser-welded joints to $57 \%$ of that of the BM $[18,19]$. Therefore, the formability of welded joints is significantly influenced by the chemistry due to the increase in FZ hardness with the increase in CE. Many studies on medium Mn steel welded joints have focused on tensile properties [20-22]. However, research on the formability of the BM and welded joint of medium Mn steel are considerably less extensive than that of other AHSSs. It has been reported that the one-step forming process is suitable for the part of medium Mn steel with complex shape because the transformation-induced plasticity (TRIP) effect during the one-step forming process contributes to high plasticity [23]. However, the two-step forming process decreases the uniformity of mechanical properties, which decreases the final formability [23]. Many studies have shown that the warm stamping technology could be used for medium Mn steel according to the actual component production [5,24]. Lun et al. [25] investigated the mechanical properties of the laser welds of medium Mn steel. They found that the formability of the welded joint only reached $5.6 \%$ of that of the BM. The joints exhibited characteristics of brittleness during the biaxial stretch forming test due to the martensite in FZ, which limited the formability of welds. However, the effects of the welding parameter on formability have not been studied. Thus, it is urgent to conduct a study on the formability of medium Mn steel, especially for the welded joints of medium Mn steel.

For that reason, in this study, the formability of medium Mn steel and its joints welded by fiber laser and gas tungsten arc welding (GTAW) were investigated by the Erichsen cupping test and finite element (FE) analysis. Details of the crack location and propagation path were also examined. Furthermore, the formability failure mode of medium Mn steel welded joints was investigated at a microscale level.

\section{Materials and Methods}

\subsection{Materials and Welding Parameters}

A $2 \mathrm{~mm}$ thick cold rolled medium Mn steel was welded by a fiber laser (IPG YLS-2000) and a GTAW machine (Miller dynasty-700, Miller, WI, USA). No filler material was used in either of the welding methods. The chemical composition of the medium $\mathrm{Mn}$ steel is listed in Table 1. The steel sheet was cut to a dimension of $100 \mathrm{~mm} \times 100 \mathrm{~mm} \times 2 \mathrm{~mm}$ and then welded parallel and perpendicular to the rolling direction. The laser power of $1.5-2 \mathrm{~kW}$ was selected with the welding speed ranging $0.9-4.8 \mathrm{~m} / \mathrm{min}$. The spot size and focus length were 0.27 and $200 \mathrm{~mm}$, respectively. The defocus amount was $0 \mathrm{~mm}$. The welding parameters of GTAW and laser are listed in Tables 2 and 3, and Figure 1. The shielding gas was pure argon gas (99.99\%) with a flow of $20 \mathrm{~L} / \mathrm{min}$. In addition, the overlap rate was taken into account when calculating the GTAW heat input.

Table 1. Chemical composition of medium Mn steel.

\begin{tabular}{cccccccc}
\hline Element & $\mathbf{C}$ & $\mathbf{M n}$ & $\mathbf{S i}$ & $\mathbf{P}$ & $\mathbf{S}$ & $\mathbf{N}$ & $\mathbf{F e}$ \\
\hline $\mathrm{wt} \%$ & 0.1 & 4.86 & 0.01 & 0.008 & 0.002 & 0.003 & Bal. \\
\hline
\end{tabular}


Table 2. Welding parameters of laser welding.

\begin{tabular}{cccccc}
\hline $\begin{array}{c}\text { Welding } \\
\text { Method }\end{array}$ & Power & $\begin{array}{c}\text { Focus Length } \\
(\mathbf{m m})\end{array}$ & $\begin{array}{c}\text { Heat Input } \\
\mathbf{( J / c m )}\end{array}$ & $\begin{array}{c}\text { Welding } \\
\text { Speed (m/min) }\end{array}$ & $\begin{array}{c}\text { Shielding Gas } \\
\text { Flow (L/min) }\end{array}$ \\
\hline \multirow{4}{*}{ Laser } & 1500 & 200 & 1000 & 0.9 & 20 \\
welding & 2000 & 200 & 1000 & 1.2 & 20 \\
& 2000 & 200 & 500 & 2.4 & 20 \\
& 2000 & 200 & 333 & 3.6 & 20 \\
\hline
\end{tabular}

Table 3. Welding parameters of gas tungsten arc welding (GTAW).

\begin{tabular}{cccccc}
\hline $\begin{array}{l}\text { Welding } \\
\text { Method }\end{array}$ & $\begin{array}{c}\text { Pulse Current } \\
\text { (A) }\end{array}$ & Voltage (V) & $\begin{array}{c}\text { Heat Input } \\
(\mathrm{J} / \mathrm{cm})\end{array}$ & $\begin{array}{c}\text { Welding } \\
\text { Speed (m/min) }\end{array}$ & $\begin{array}{c}\text { Shielding Gas } \\
\text { Flow (L/min) }\end{array}$ \\
\hline \multirow{3}{*}{ GTAW } & $\begin{array}{l}\mathrm{I}_{\mathrm{p}}=140 \mathrm{~A} \\
\mathrm{~T}_{\mathrm{p}}=0.1 \mathrm{~s}\end{array}$ & 11.7 & 4826.25 & 0.12 & 20 \\
& $\begin{array}{l}\mathrm{I}_{\mathrm{b}}=25 \mathrm{~A} \\
\mathrm{~T}_{\mathrm{b}}=0.1 \mathrm{~s}\end{array}$ & & & & \\
\hline
\end{tabular}

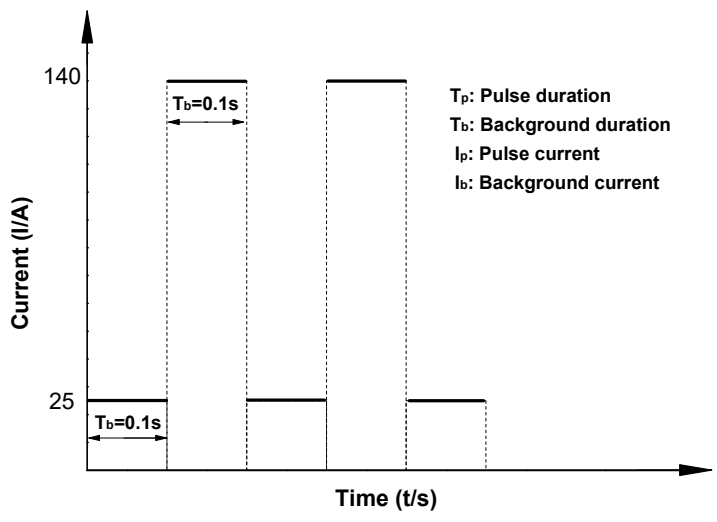

Figure 1. Main parameters of the pulse signal for GTAW.

\subsection{Microstructural Characterization and Mechanical Property Test}

The microstructure of the BM and welded joints was observed by optical microscopy (OM) and scanning electron microscopy (SEM), respectively. The uniaxial tensile tests of the welded joint and hardening zone (HZ) were performed on the mechanical testing system (MTS) at room temperature with a strain rate of $1.5 \times 10^{-3} \mathrm{~s}^{-1}$. The size of the welded joint and $\mathrm{HZ}$ tensile samples is shown in Figure $2 a, b$, respectively. The microhardness of the welded joint was evaluated by the microhardness tester with a load of $200 \mathrm{~g}$. The formability of the welded joints and the BM was tested on a cupping testing machine according to the GB/T 4156-2007 standards. The dimension of the hemispherical punch was $20 \mathrm{~mm}$ diameter with locked specimen edges, as shown in Figure 3a. The hemispherical punch was located at the center of the weld seam with a travel speed of $7 \mathrm{~mm} / \mathrm{min}$. A graphitic lubricant was laid over the surface of specimens before the cupping test. 
(a)
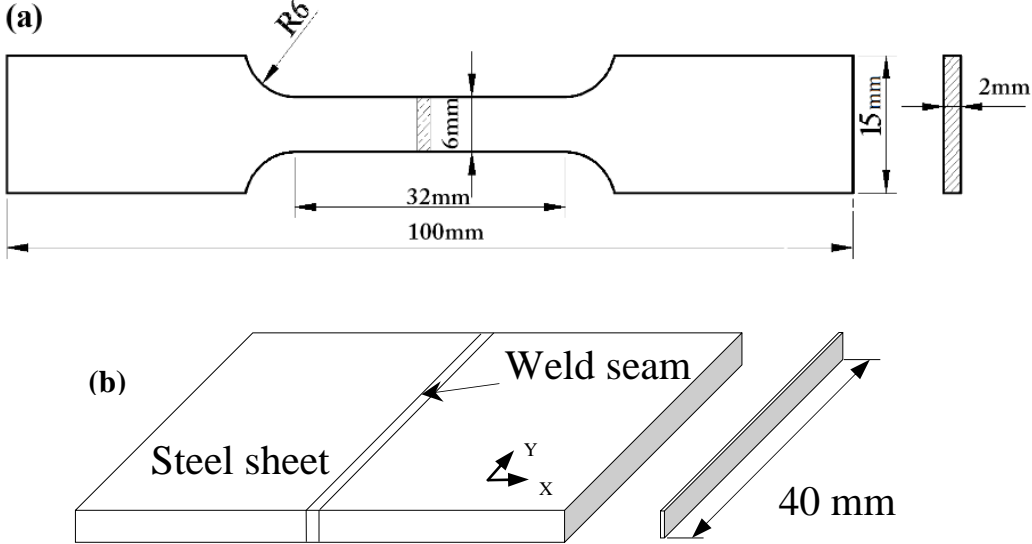

Figure 2. Schematic of the uniaxial tensile test sample of (a) welded joints and (b) hardening zone (HZ).
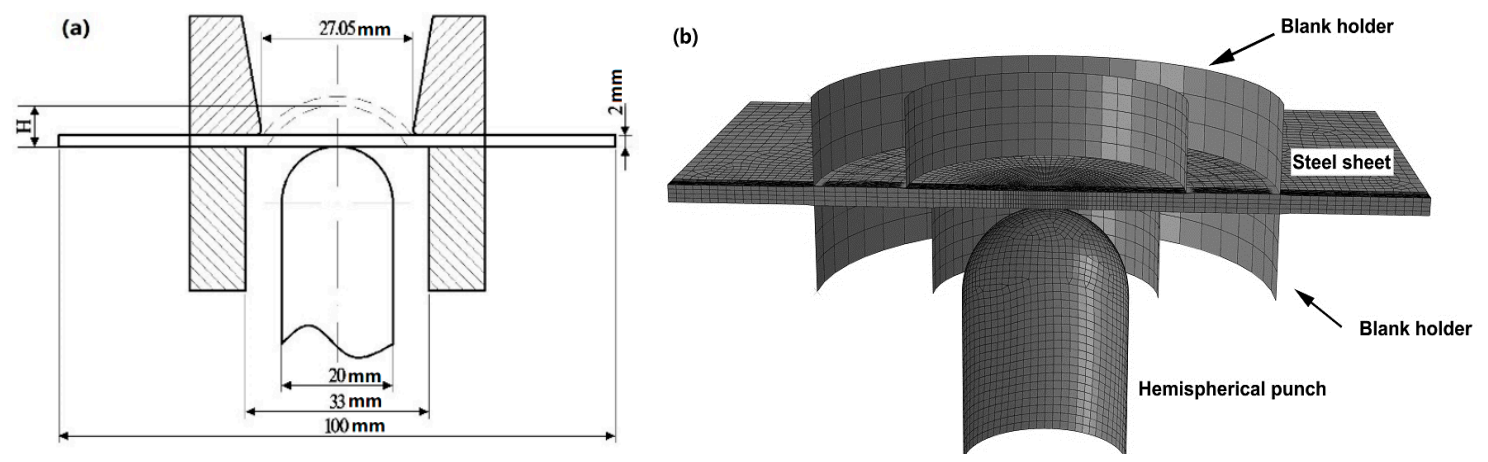

Figure 3. Schematic and finite element modeling of the Erichsen cupping test of welded joints:

(a) experiment schematic and (b) finite element modeling.

\subsection{Cupping Test FE Simulation}

Numerical simulation for the cupping test of welded joints and the BM was conducted using the Abaqus 6.14 software produced by Dassault Systemes Simulia Corp., Providence, RI, USA. The set-up of the cupping test for the FE model is depicted in Figure 3b. The punch and joint holder were set as rigid surfaces with a four-node shell, and the sheet was set as an eight-node hexahedral element. Considering the structural symmetry, half of the cupping test model analysis was used to reduce the calculation time. To achieve more accurate results, the element mesh generation method was used for the sheet in this simulation study. The basic grid size was $0.25 \mathrm{~mm}$, which was refined to $0.1 \mathrm{~mm}$ in the contact area. Four layers of grid were set in the thickness direction of the steel sheet. The laser-welded joint of medium Mn steel had no softened zone. To simplify the model, the welded joint was modeled as $\mathrm{HZ}$ and $\mathrm{BM}$ based on the assumption each zone was uniform in terms of mechanical property. The von Mises yield criteria was applied in this simulation, which is shown in Equations (1) and (2).

$$
\begin{gathered}
\sigma_{e}=\sigma_{y} \\
\sigma_{e}=\frac{1}{2} \sqrt{\left(\sigma_{1}-\sigma_{2}\right)^{2}+\left(\sigma_{2}-\sigma_{3}\right)^{2}+\left(\sigma_{3}-\sigma_{1}\right)^{2}}
\end{gathered}
$$

where $\sigma_{\mathrm{e}}$ is the effective stress; $\sigma_{\mathrm{y}}$ is the yield strength; and $\sigma_{1}, \sigma_{2}, \sigma_{3}$ are the principal stress in the $X, Y$, and $Z$ direction in Cartesian coordinates, respectively. The constitutive model for plastic deformation is represented by the Hollomon equation [14,26]:

$$
\sigma=K \varepsilon^{n}=K\left(\varepsilon_{y p}+\varepsilon_{p}\right)^{n}
$$


where $\sigma$ is the flow stress; $K$ is the strength coefficient; $n$ is the strain hardening exponent; and $\varepsilon_{\mathrm{yp}}$ and $\varepsilon_{\mathrm{p}}$ are the strain of yield and effective plastic strain, respectively. To investigate the influence of the width and strength of the HZ on formability, the welded joint was modelled by defining four kinds of width based on the experimental results. The maximum plastic strain was adopted as the failure criteria for the BM and welded joints during the cupping test.

\section{Results}

\subsection{Microstructure and Microhardness}

The microstructure of a typical welded joint and BM is shown in Figure 4. The metallographic morphology of the laser-welded joint is shown in Figure 4a. Due to the sharp temperature gradient, a clearly visible fusion line was observed in the laser-welded joint between the FZ and HAZ. The microstructure of the laser-welded FZ was martensite, and the HAZ was fine-grain martensite and austenite, as shown in Figure $4 b$,c. The microstructure of the FZ welded by GTAW was martensite, as shown in Figure 4d. The individual prior-austenite are marked with a yellow dotted line in the figure. The lath martensite exhibited clear block structures. The BM was composed of ferrite and austenite, as shown in and Figure 4f. The grain size of laser-welded FZ was finer than that of GTA-welded FZ. Coarse martensite was transformed from austenite at the superheated zone during the rapid cooling process in welding [21].
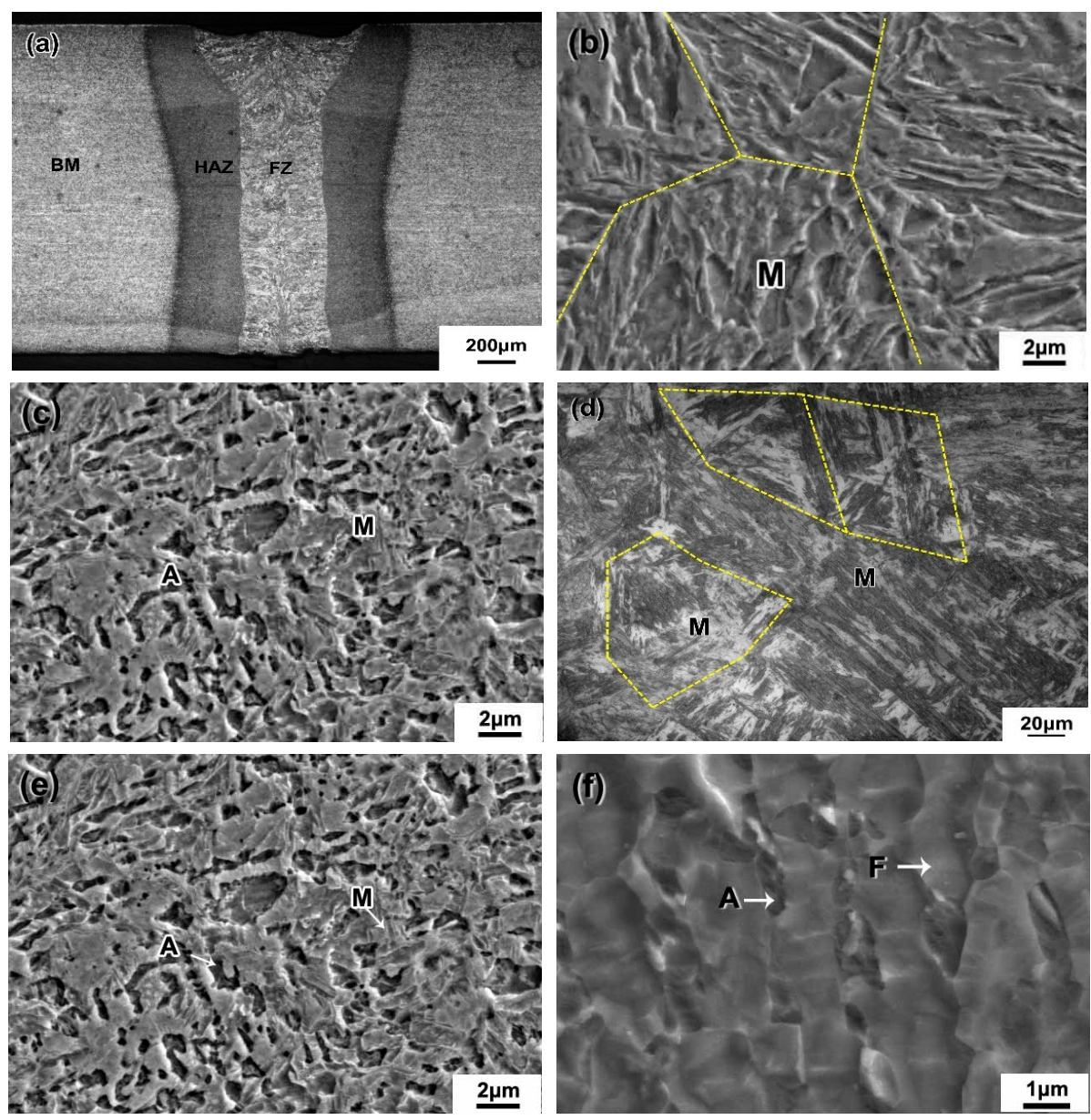

Figure 4. Microstructure of a typical welded joint and base metal (BM). (a) Overview; (b) SEM image of the fusion zone (FZ); (c) SEM image of the heat-affected zone (HAZ) of the laser-welded joint; (d) optical microscopy (OM) image of the FZ in the GTA-welded joint; (e) SEM image of the HAZ in the GTA-welded joint; (f) SEM image of the BM. 
The microhardness of the laser- and GTA-welded joints is shown in Figure 5a,b, respectively. It was evident that there was no softened zone in the laser- or GTA-welded joints. There were clearly big differences between the microhardness of the FZ and the HAZ. Supercritical HAZ of both the laser- and GTA-welded joints close to the FZ exhibited the highest hardness with a value of $450 \mathrm{HV}$ as a result of the fine-grain martensitic microstructure [27]. However, the microhardness of the FZ was slightly lower than that of the supercritical HAZ. Thus, the HZ not only comprised the FZ but also included part of the HAZ. From the weld central line to the BM, the microhardness declined sharply due to the reduction of the volume fraction of martensite, especially in the high-speed laser-welded joint. Accordingly, the HZ was defined as being from one side of the HAZ with the hardness over $350 \mathrm{HV}$ to another that included the FZ. This was due to the microstructure of this area being mainly martensite with a volume fraction exceeding $70 \%$. The average microhardness of the FZ at different welding speeds is shown in Figure 6a. It can be seen that the microhardness increased with increasing welding speed. The FZ microhardness of the GTA-welded joint $(395 \mathrm{HV})$ was lower than that of laser-welded joint (415-450 HV), which was due to the difference in the cooling rate and heat input between the two welding methods.
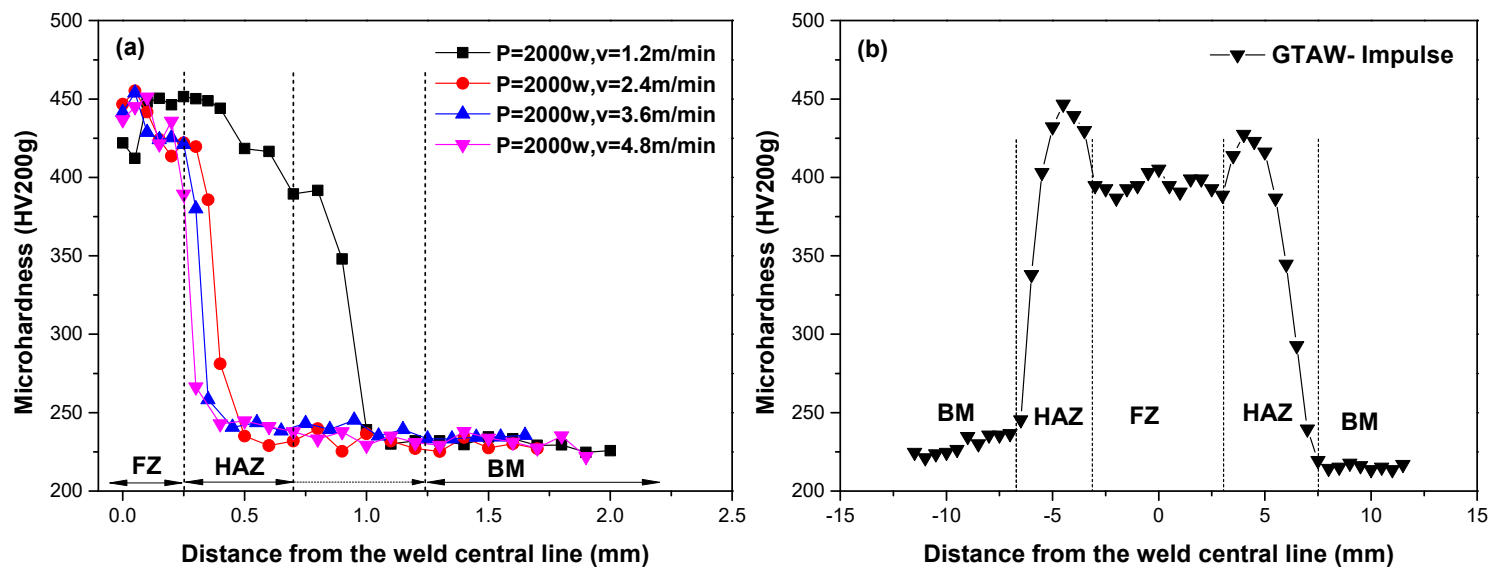

Figure 5. The microhardness distribution of (a) laser-welded joint and (b) GTA-welded joint.
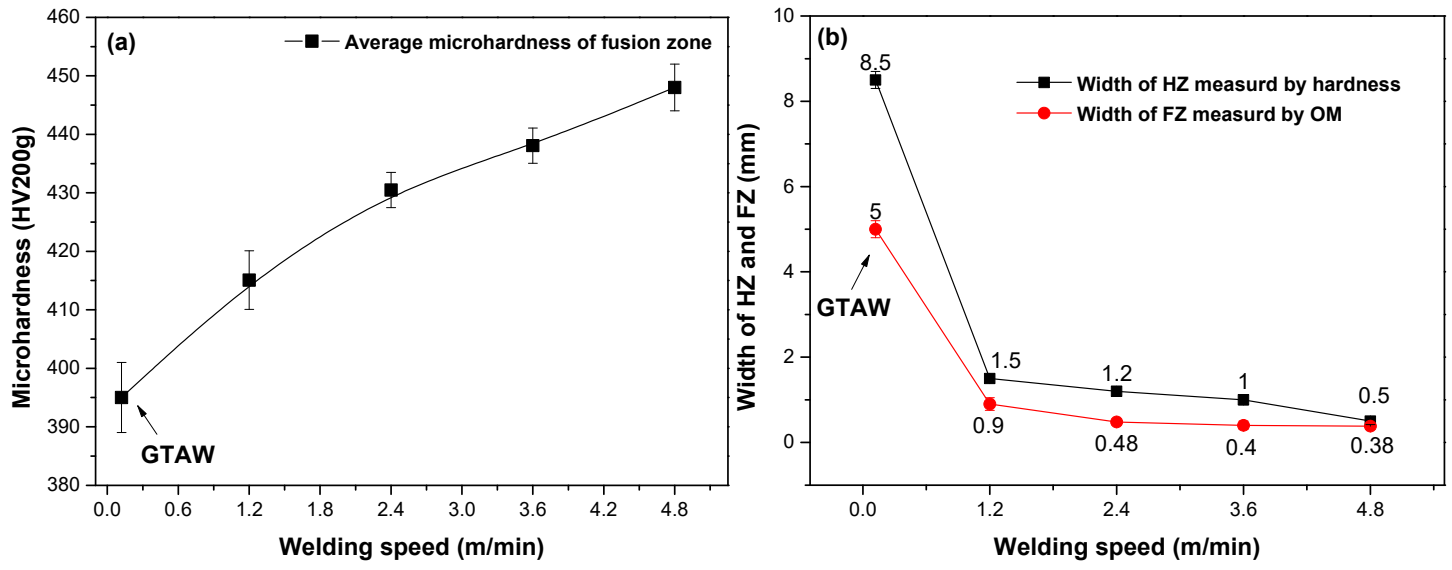

Figure 6. Microhardness and width of the FZ and HZ at different welding speeds: (a) average microhardness of the FZ and (b) width of the FZ and HZ.

The FZ width was obtained by the average width of the top, middle, and bottom of the FZ according to the OM image, and the $\mathrm{HZ}$ width was measured by the hardness profile of each welded joint, as shown in Figure 6b. The widths of the HZ and FZ decreased with increasing welding speed, but the degree of decline was reduced due to the small variability of heat input in laser welding. 
High-speed welding meant the duration time at the high temperature was shorter, which resulted in a steep temperature gradient, forming narrower $\mathrm{HZ}$ and FZ. The width of the $\mathrm{HZ}$ and FZ in the GTA-welded joint was wider than that in the laser-welded joints as a result of larger heat input and slower welding speed during the GTAW process.

\subsection{Tensile Properties}

The mechanical properties of the welded joint and the HZ, such as ultimate tensile strength (UTS), yield strength (YS), and elongation, are shown in Figure 7. The UTS and YS of the welded joint were equal to those of the BM as the fracture was located at the BM. However, the HZ of the welded joint exhibited superhigh strength exceeding $1200 \mathrm{MPa}$ due to the martensitic microstructure. Meanwhile, the UTS and YS of the HZ presented a slight tendency to increase with increasing welding speed. Figure $7 \mathrm{~b}$ shows the elongation of the welded joint and the HZ. It can be seen that the elongation of the welded joint increased gradually with increasing welding speed, which resulted from the decrease in the width of the HZ [21]. However, the elongation of the HZ decreased with increasing welding speed. It was less than $8 \%$ for laser-welded HZ and 15\% for GTA-welded HZ due to the worse ductility of martensite.
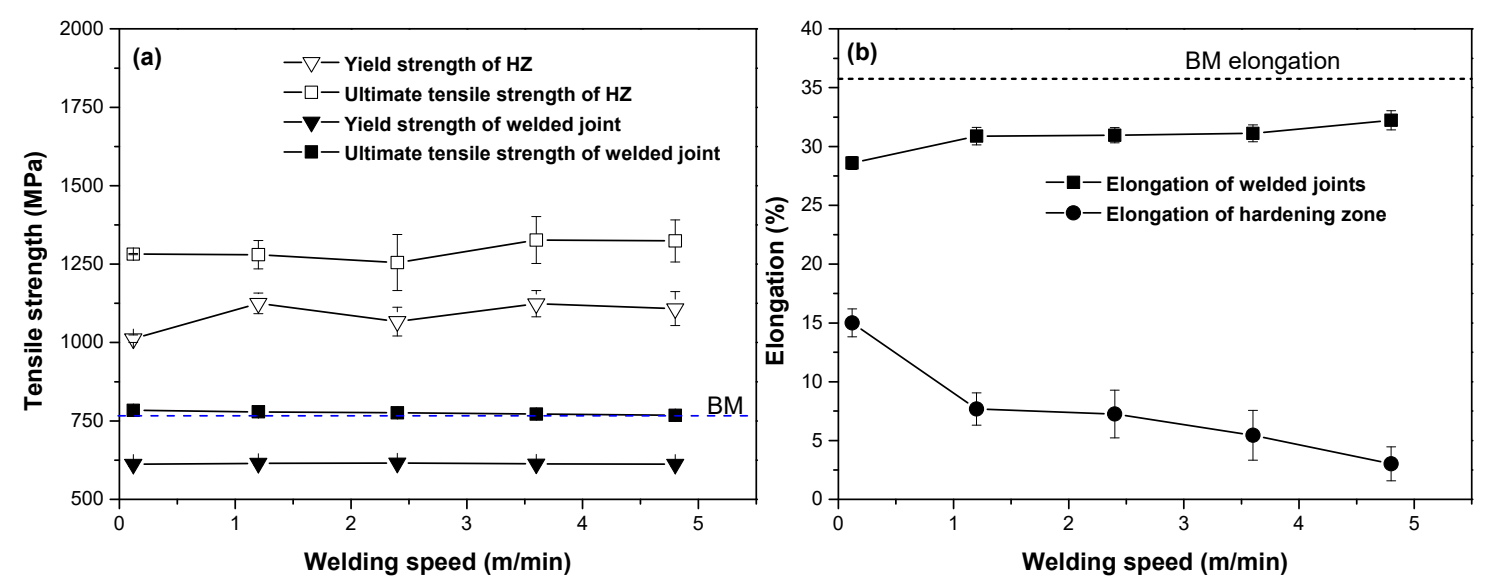

Figure 7. The mechanical properties of (a) ultimate tensile strength (UTS) and yield strength (YS); (b) elongation of the welded joints and HZ.

Notably, the UTS of the HZ was very close to that of the GTA-welded HZ, but the elongation was very different. The typical fracture surface morphology of the HZ in GTA- and laser-welded joints is shown in Figure 8. The GTA-welded HZ exhibited the characteristics of shallow dimples, indicating ductile fracture, while the laser-welded $\mathrm{HZ}$ showed the characteristics of a small cleavage step, indicating cleavage fracture. The cooling rate was different between laser welding and GTAW. Higher cooling rate results in higher hardening stresses of the HZ, which reduces the ductility of the HZ [28-30]. Thus, the laser-welded HZ and GTA-welded HZ showed ductile and cleavage fracture characteristics, respectively.

The strain hardening exponent $n$ represents the uniform deformation ability of the material during the tensile test before local necking and fracturing [14]. A higher value of $n$ means a stronger work-hardening ability and more uniform stretchability. The BM strain hardening exponent was 0.27 as measured by the tensile testing curve, which was higher than that of several AHSSs, such as high-strength low-alloy (HSLA) and DP steel [14]. The plastic strain ratio ( $R$ value) is an important parameter for a steel sheet as it is an indication of the resistance to fracture as a result of thinning during deep drawing [23]. The plastic strain ratio of the longitudinal and transverse direction in the BM was 0.89 and 0.93 , respectively. This shows that the $R$ value was very close to 1 , the index of an isotropic material, which meant the width strain and thickness strain were synchronous during tensile 
test [23]. These data indicate that the mechanical property of medium Mn steel is characteristic of isotropic materials.
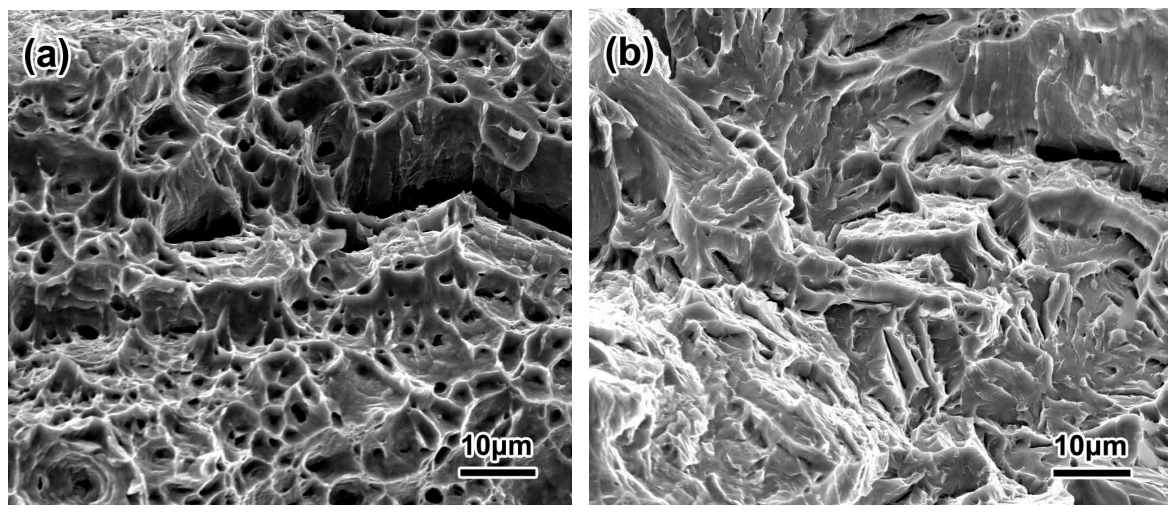

Figure 8. The fracture surface morphology of (a) GTA-welded HZ and (b) laser-welded HZ (2 kW, $1.2 \mathrm{~m} / \mathrm{min})$.

\subsection{Erichsen Cupping Test}

The Erichsen cupping test results of the BM and welded joints are shown in Figure 9. The GTA-welded joint had the worst cupping value $(6.8 \mathrm{~mm})$, and the laser-welded joint with the fastest welding speed had the best cupping value $(9.17 \mathrm{~mm})$. However, the cupping value of both joints was lower than that of the BM (13.88 mm), as shown in Figure 9a. The formability of the welded joints indicated a tendency to increase with increasing welding speed. To verify the influence of the welding direction on the formability of welded joints, both parallel and perpendicular welding to the rolling direction were adopted in the laser welding process, and the results are shown in Figure 9b. Due to the isotropy of the BM, the welding direction had little effect on the formability of welded joints, although parallel welding to the rolling direction had a slight advantage for formability. Welding with the same heat input, the HZ width of the two welded joints was $1.8 \mathrm{~mm}(1500 \mathrm{w}, 0.9 \mathrm{~m} / \mathrm{min})$ and $1.5 \mathrm{~mm}(2000 \mathrm{w}$, $1.2 \mathrm{~m} / \mathrm{min}$ ) respectively. The latter had better formability compared to the former welded joint.
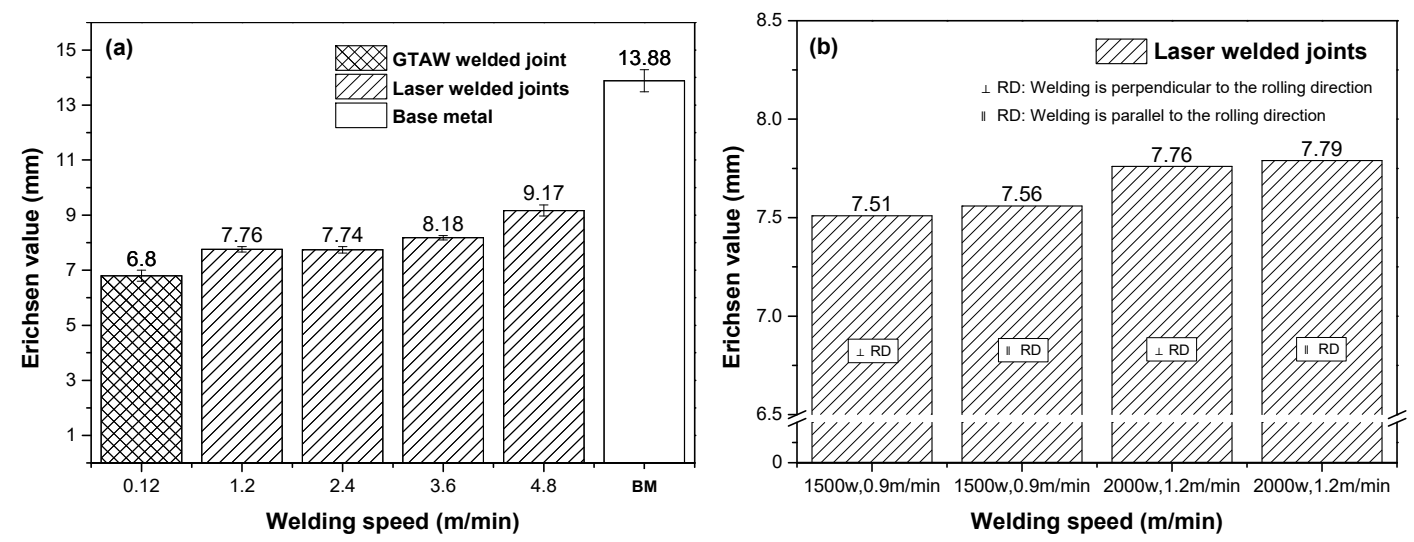

Figure 9. Erichsen cupping values of (a) welded joints with different welding speed and BM; (b) welded joints with different welding directions.

The top views of the forming samples of welded joints and BM that were tested are shown in Figure 10. All the cupping cracks initiated at the $\mathrm{HZ}$ and propagated perpendicular to the welding direction. The cupping test of the BM fractures with a crescent-shaped path around the center of the dome is shown in Figure 10f. The HZ reached the deformation limit first and then failed during the cup testing because its ductility was worse than that of the BM. It can be noted that the crack was invariably on the side of the central dome. 

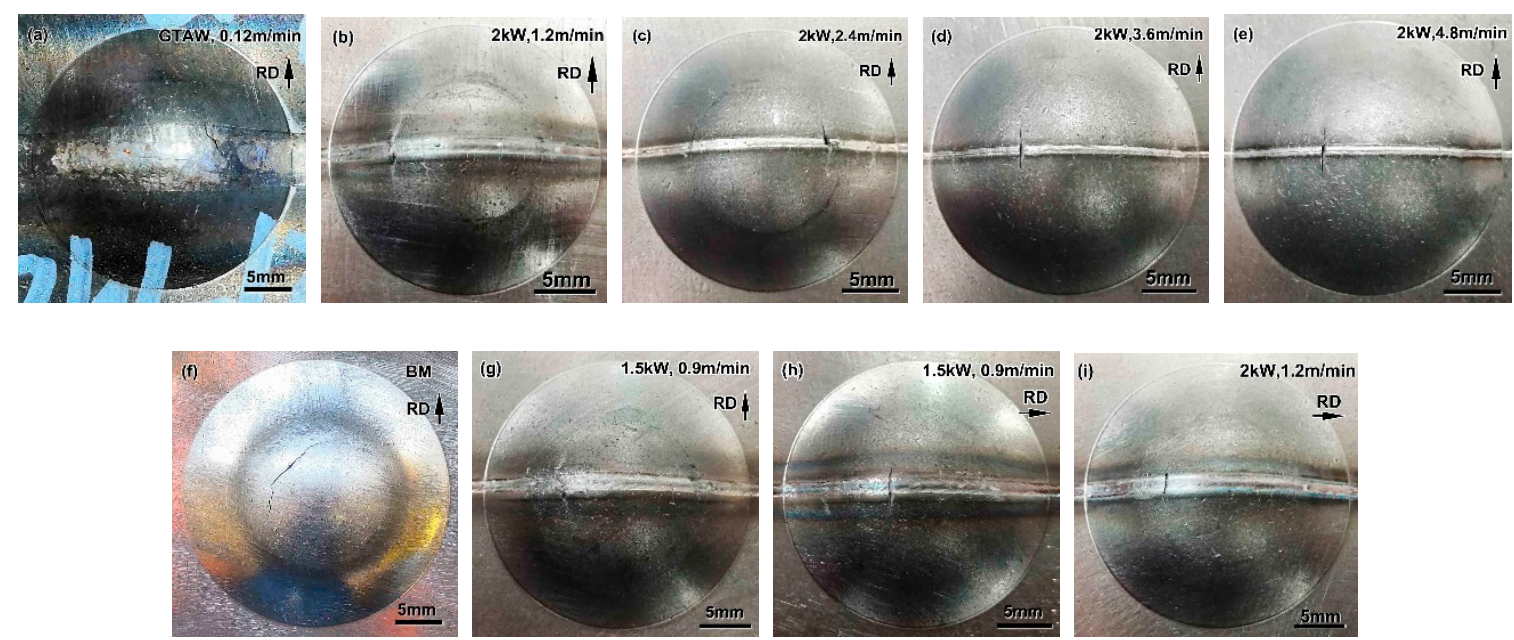

Figure 10. The top views of the cupping specimens that were tested, (a) GTAW welded joint, (b-e) and (g) laser welded joint with welding perpendicular to the rolling direction (RD), (f) base metal, (h) and (i) laser welded joint with welding parallel to RD.

The experimental and simulated cupping test result and the formability ratio $(r)$ of the welded joint are shown in Figure 11a,b, respectively. The formability ratio of the welded joint is represented by $H_{\mathrm{w}} / H_{\mathrm{b}}[9,21]$, where $H_{\mathrm{w}}$ and $H_{\mathrm{b}}$ are the Erichsen value of welded joints and BM, respectively. Typical strain distribution of the welded joints with $\mathrm{HZ}$ of different widths is shown in Figure 12. The results indicate that the forming strain of the welded joint with narrow $\mathrm{HZ}$ concentrated on the BM, while the forming strain of the welded joint with wide $\mathrm{HZ}$ concentrated on the HZ.
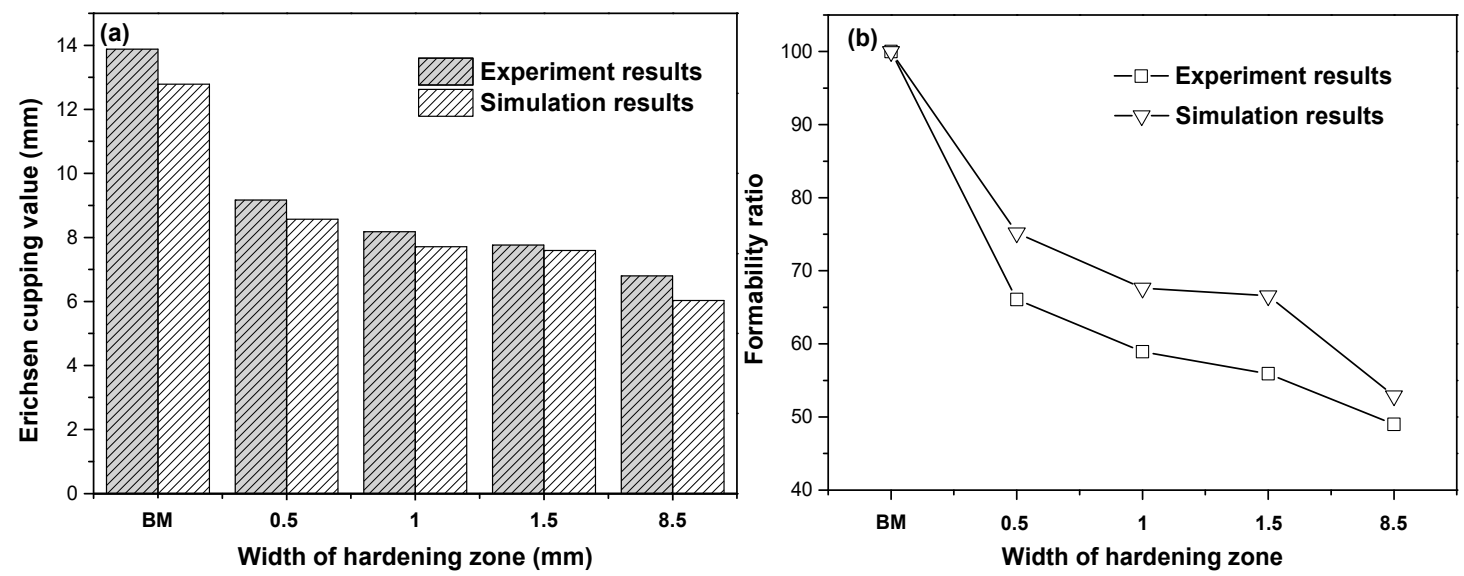

Figure 11. Experimental and simulated result of (a) cupping values and (b) the formability ratio. 
PE-Global-Plastic strain components(YZ. Max)

(a)

Global System

Advanced Average

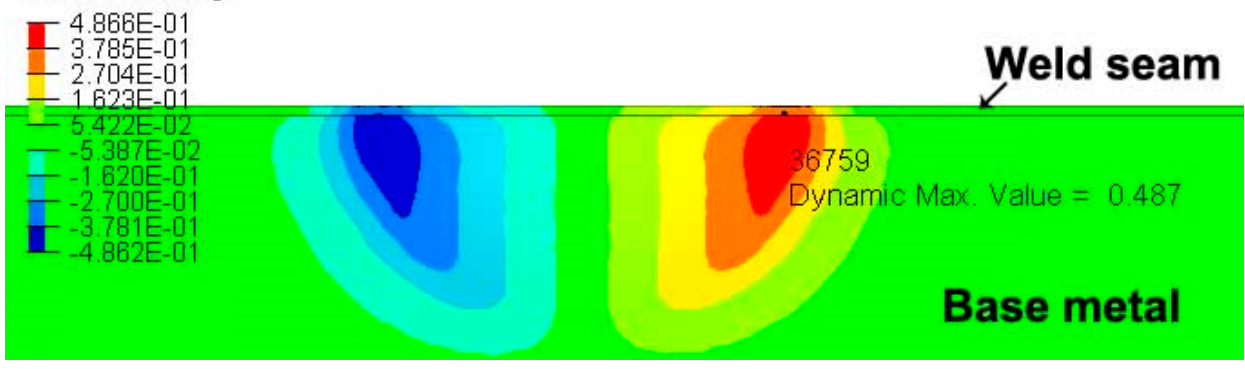

PE-Global-Plastic strain components(YZ. Max)

(b)

Global System

Advanced Average

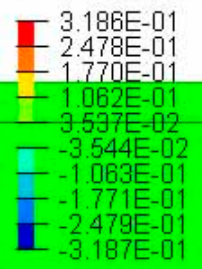

Weld seam

Dynamic Max. Value $=0.319$

Base metal

Figure 12. Strain distribution of welded joints of (a) $0.5 \mathrm{~mm} \mathrm{HZ}$ and (b) $8.5 \mathrm{~mm} \mathrm{HZ}$ during the cupping test.

Typical fracture surface macroscopic morphology of the cupping test of the BM is shown in Figure 13a. It can be seen that the cupping test crack initiation was located at the top surface of the $\mathrm{BM}$. The crack initiation was located at the point of maximum strain, which was the crack source; the detailed characteristic is shown in Figure 13b. The morphology around the crack source exhibited an annular extension, which occurred as a result of biaxial stretch forming during the cupping test. The magnified images of the annular extension zone of the BM are shown in Figure 13c, d The fracture surface was characteristic of a ductile fracture, showing lamellar tearing due to grain stretching during the biaxial stretch forming process. The morphology of the fracture surface of the welded joint cupping test sample is shown in Figure 13e. It can be seen that the cupping test crack initiation was located at the HZ. The whole fracture surface also displayed annular extension characteristics. However, the failure morphology of the $\mathrm{HZ}$ was characteristics of brittle and lamellar tearing mixture, which was different from that of the BM, and the spacing of the lamellar tearing was wider than that of the BM, as shown in Figure 13f-h. 


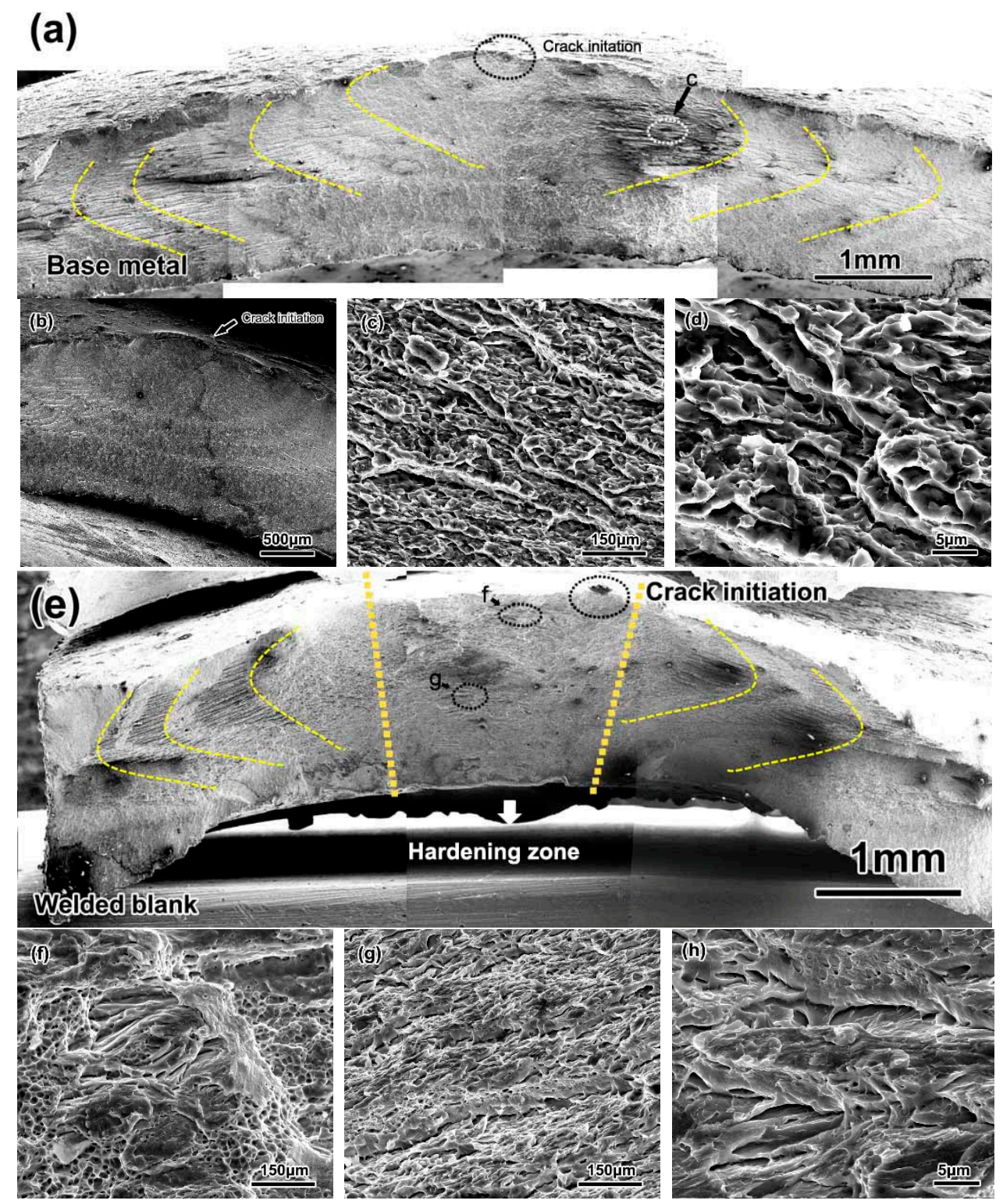

Figure 13. Typical fracture surface morphology of cupping test of (a-d) BM and (e-h) laser-welded joint $(2 \mathrm{~kW}, 1.2 \mathrm{~m} / \mathrm{min})$.

\section{Discussion}

\subsection{Effect of the HZ on the Formability of Welded Joints}

Research has indicated that the formability of welded joints is influenced by the heat input $[15,31]$. However, in this study, the formability of the welded joint showed differences with the same heat input. When the heat input was $100 \mathrm{~J} / \mathrm{mm}$, the welded joint with higher welding speed had better formability, as shown in Figure 9b. The difference between the two welded joints was the width of the HZ. Experimental and simulation results indicated that the formability ratio decreased with increasing width of the HZ. The width of the HZ decreased with increasing welding speed, but the opposite was true for the hardness. In general, the higher the hardness, the lower was the ductility, but the welded joint with high-speed laser welding exhibited the best formability, whereas the GTA-welded joint exhibited the worst formability. This indicated that the major influencing factor on the formability of the welded joints was the width of the HZ rather than the ductility of the HZ. The simulation results also proved this conclusion. 
The uniaxial tensile test results of the BM in different directions showed that the plastic strain ratio in the longitudinal and transverse directions was very close to 1 , and the $n$ value of the $B M(0.27)$ was much larger than that of the HZ ( 0.19), which meant the uniform deformation capability of the $\mathrm{BM}$ was larger than that of the HZ. Therefore, the cupping value of the BM was much higher than that of the welded joints. The deformation of the welded joints was not uniform during the cupping test. As the formability test is a biaxial stretch forming mode, the forming samples were subjected to tensile stress in two directions [10,32]. In the uniaxial tensile test of the welded joints, the fracture failed at the BM zone, which meant the strain of the welded joints was mainly distributed in the BM rather than the HZ. Furthermore, the width of the HZ decreased with increasing welding speed, which resulted in an increase in the elongation of the welded joints. In the uniaxial tensile test of the $\mathrm{HZ}$, the yield strength of all the $\mathrm{HZ}$ exceeded $1000 \mathrm{MPa}$, while the fluctuation range was small. Hence, the fluctuation of the hardness and strength in the $\mathrm{HZ}$ was not enough to affect the formability. Therefore, increasing the welding speed resulted in a decrease in the width of the HZ, which resulted in an increase in the formability of the welded joints.

\subsection{Cupping Crack Initiation and Propagation of Welded Joints}

The tensile test results of the welded joints and the HZ showed that the elongation of the welded joints was much higher than that of the HZ. Therefore, the HZ reached the maximum limit of strain early during the cupping test of the welded joints due to its worse ductility, which resulted in crack initiation at the HZ. The hardness of the HZ was higher than that of the BM, but the elongation was lower. The formability crack propagated along the lower hardness and strength direction, which resulted in a crack that propagated perpendicular to the welding direction.

In addition, the simulation results also indicated that the maximum plastic strain of the welded joints was located at one side of the center of the dome, and the plastic strain was negative on the other side of the center of the dome. This meant the HZ tensile loading direction of the two sides of the center of the dome was opposite, and the tensile strain was a little larger than that of the compressive strain. Therefore, the weld seam of both sides of the center dome was inhomogeneous with respect to the deformation during the cupping test. This led to failure on the side of the center of the dome with higher tensile stress. During the Erichsen cupping test, the steel sheet was subjected to biaxial stress. The internal surface of the cupping sample was subjected to compression stress, but the outside surface was subjected to the stretch stress [23], which resulted in the annular extension morphology. Moreover, due to difference in the constitution of the microstructure in the HZ, the difference in properties between microstructures was bigger. This facilitated the formation of the microcrack at the interface as a result of uncoordinated deformation of ferrite or austenite and martensite [27,33]. In addition, the welded seam surface inevitably contained microdefects, which were formed by the concentration of stress, and the macrocrack was then formed during the cupping test.

\section{Conclusions}

Laser welding and GTAW were conducted on medium Mn steel. The formability of the BM and welded joints were evaluated by the Erichsen cupping test and numerical simulation. The following conclusions can be drawn:

(1) Medium Mn steel shows good formability, which is attributed to its excellent ductility in the uniaxial tensile test. Medium Mn steel has isotropic characteristics, which result in a fracture surface with a crescent-shaped path around the center of the dome during the Erichsen cupping test.

(2) Due to the existence of the HZ, the Erichsen cupping value of the welded joints is lower than that of the BM, and the formability ratio can reach $66 \%$. The welding direction has little influence on the formability due to the isotropy of medium Mn steel. 
(3) The primary influencing factor on formability is the width of the HZ in welded joints, and the secondary factor is the strength and ductility of the HZ. The formability ratio of the welded joints increases due to the decrease in the width of the HZ with increasing welding speed.

(4) The initiation of the Erichsen cupping crack is located in the HZ and invariably propagates perpendicular to the welding direction due to the worse ductility of the HZ.

Author Contributions: Y.C. and L.Z. designed the experiments. Y.C. performed the experiments. Y.C., L.Z., and Y.P. analyzed the SEM and mechanical property data. B.W. and H.Z. analyzed the FE simulation of the cupping test. M.Z., L.Z., and Z.T. contributed to the interpretation of the results and the writing of the final version of the manuscript. All authors have read and agreed to the published version of the manuscript.

Funding: This research was funded by the National Key R \& D Program of China, grant number 2016YFB1101100" and the International Science and Technology Cooperation of China, grant number 2015DFA51460.

Acknowledgments: The authors gratefully acknowledge financial support by the National Key R \& D Program of China and the International Science and Technology Cooperation of China.

Conflicts of Interest: The authors declare no conflict of interest.

\section{References}

1. Liu, C.; Peng, Q.; Xue, Z.; Wang, S.; Yang, C. Microstructure and Mechanical Properties of Hot- Rolled and Cold-Rolled Medium-Mn TRIP Steels. Materials 2018, 11, 2242. [CrossRef] [PubMed]

2. Ma, Y.; Song, W.; Zhou, S.; Schwedt, A.; Bleck, W. Influence of Intercritical Annealing Temperature on Microstructure and Mechanical Properties of a Cold-Rolled Medium-Mn Steel. Metals 2018, 8, 357. [CrossRef]

3. Podany, P.; Reardon, C.; Koukolíková, M.; Procházka, R.; Franc, A. Microstructure, Mechanical Properties and Welding of Low Carbon, Medium Manganese TWIP/TRIP Steel. Metals 2018, 8, 263. [CrossRef]

4. Ma, Y. Medium-manganese steels processed by austenite-reverted-transformation annealing for automotive applications. Mater. Sci. Technol. 2017, 33, 1713-1727. [CrossRef]

5. Wang, C.; Li, X.; Han, S.; Zhang, L.; Chang, Y.; Cao, W.; Dong, H. Warm Stamping Technology of the Medium Manganese Steel. Steel Res. Int. 2017, 89, 1700360. [CrossRef]

6. Rossini, M.; Spena, P.R.; Cortese, L.; Matteis, P.; Firrao, D. Investigation on dissimilar laser welding of advanced high strength steel sheets for the automotive industry. Mater. Sci. Eng. A 2015, 628, $288-296$. [CrossRef]

7. Panda, S.K.; Baltazar-Hernandez, V.H.; Kuntz, M.; Zhou, Y. Formability Analysis of Diode-Laser-Welded Tailored Blanks of Advanced High-Strength Steel Sheets. Met. Mater. Trans. A 2009, 40, 1955-1967. [CrossRef]

8. Sreenivasan, N.; Xia, M.; Lawson, S.; Zhou, Y. Effect of Laser Welding on Formability of DP980 steel. J. Eng. Mater. Technol. 2008, 130, 041004. [CrossRef]

9. Xia, M.; Sreenivasan, N.; Lawson, S.; Zhou, Y.; Tian, Z. A Comparative Study of Formability of Diode Laser Welds in DP980 and HSLA Steels. J. Eng. Mater. Technol. 2007, 129, 446-452. [CrossRef]

10. Panda, S.K.; Li, J.; Baltazar-Hernandez, V.H.; Zhou, Y.; Goodwin, F. Effect of Weld Location, Orientation, and Strain Path on Forming Behavior of AHSS Tailor Welded Blanks. J. Eng. Mater. Technol. 2010, 132, 041003. [CrossRef]

11. Nikhare, C.P. Experimental and Numerical Investigation of Forming Limit Differences in Biaxial and Dome Test. J. Manuf. Sci. Eng. 2018, 140, 081005. [CrossRef]

12. Spena, P.R.; Cortese, L.; Nalli, F.; Májlinger, K. Local formability and strength of TWIP-TRIP weldments for stamping tailor welded blanks (TWBs). Int. J. Adv. Manuf. Technol. 2018, 101, 757-771. [CrossRef]

13. Xia, M.; Kuntz, M.; Tian, Z.; Zhou, Y. Failure study on laser welds of dual phase steel in formability testing. Sci. Technol. Weld. Join. 2008, 13, 378-387. [CrossRef]

14. Panda, S.K.; Kuntz, M.L.; Zhou, Y. Finite element analysis of effects of soft zones on formability of laser welded advanced high strength steels. Sci. Technol. Weld. Join. 2009, 14, 52-61. [CrossRef]

15. Ahmed, E.; Reisgen, U.; Schleser, M.; Mokrov, O. On formability of tailor laser welded blanks of DP/TRIP steel sheets. Sci. Technol. Weld. Join. 2010, 15, 337-342. [CrossRef]

16. Peng, W.; Feng, Z.; Zheng, S. Formation quality optimization of laser hot wire cladding for repairing martensite precipitation hardening stainless steel. Opt. Laser Technol. 2015, 65, 180-188. [CrossRef] 
17. Wei, C.; Zhang, J.; Yang, S.; Sun, L.; Tao, W.; Wu, F.; Xia, W. Improving formability of laser welded automotive dual phase steels with local cooling. Sci. Technol. Weld. Join. 2015, 20, 145-154. [CrossRef]

18. Bandyopadhyay, K.; Panda, S.K.; Saha, P. Investigations Into the Influence of Weld Zone on Formability of Fiber Laser-Welded Advanced High Strength Steel. J. Mater. Eng. Perform. 2014, 23, 1465-1479. [CrossRef]

19. Bandyopadhyay, K.; Panda, S.K. Steel Processing: Formability of Steel Sheets and Tailor-Welded Blanks for Automotive Applications. Encycl. Automot. Eng. 2014, 1-26. [CrossRef]

20. Cao, Y.; Luo, C.; Zhao, L.; Peng, Y.; Song, L.; Ma, C.; Tian, Z.; Zhong, M.; Wang, Y. Microstructural evolution and mechanical properties of laser-welded joints of medium manganese steel. J. Iron Steel Res. Int. 2019, 27, 75-87. [CrossRef]

21. Cao, Y.; Zhao, L.; Peng, Y.; Ma, C.; Tian, Z.; Zhong, M. Effect of Heat Input on Microstructure and Mechanical Properties of Laser Welded Medium Mn Steel Joints. Chin. J. Lasers 2018, 45, 1102008. [CrossRef]

22. Razmpoosh, M.; Biro, E.; Goodwin, F.; Zhou, Y. Dynamic Tensile Behavior of Fiber Laser Welds of Medium Manganese Transformation-Induced Plasticity Steel. Metall. Mater. Trans. A 2019, 50, 3578-3588. [CrossRef]

23. Chang, Y.; Wang, M.; Wang, N.; Li, X.; Wang, C.; Zheng, G.; Ren, D.; Dong, H. Investigation of forming process of the third-generation automotive medium-Mn steel part with large-fractioned metastable austenite for high formability. Mater. Sci. Eng. A 2018, 721, 179-188. [CrossRef]

24. Li, X.; Chang, Y.; Wang, C.; Hu, P.; Dong, H. Comparison of the hot-stamped boron-alloyed steel and the warm-stamped medium-Mn steel on microstructure and mechanical properties. Mater. Sci. Eng. A 2017, 679, 240-248. [CrossRef]

25. Lun, N.; Saha, D.C.; Macwan, A.; Pan, H.; Wang, L.; Goodwin, F.; Zhou, Y. Microstructure and mechanical properties of fibre laser welded medium manganese TRIP steel. Mater. Des. 2017, 131, 450-459. [CrossRef]

26. Zener, C.; Hollomon, J.H. Effect of Strain Rate Upon Plastic Flow of Steel. J. Appl. Phys. 1944, 15, 22. [CrossRef]

27. Li, W.; Ma, L.; Peng, P.; Jia, Q.; Wan, Z.; Zhu, Y.; Guo, W. Microstructural evolution and deformation behavior of fiber laser welded QP980 steel joint. Mater. Sci. Eng. A 2018, 717, 124-133. [CrossRef]

28. Anawa, E.M.; Olabi, A.G. Control of welding residual stress for dissimilar laser welded materials. J. Mater. Process. Technol. 2008, 204, 22-33. [CrossRef]

29. Withers, P.J.; Bhadeshia, H. Residual stress. Part 2-Nature and origins. Mater. Sci. Technol. 2001, 17, 366-375. [CrossRef]

30. Mai, T.A.; Spowage, A.C. Characterisation of dissimilar joints in laser welding of steel-kovar, copper-steel and copper-aluminium. Mater. Sci. Eng. A 2004, 374, 224-233. [CrossRef]

31. Reisgen, U.; Schleser, M.; Mokrov, O.; Ahmed, E. Uni- and bi-axial deformation behavior of laser welded advanced high strength steel sheets. J. Mater. Process. Technol. 2010, 210, 2188-2196. [CrossRef]

32. Elshalakany, A.B.; Ali, S.; Osman, T.A.; Megaid, H.; El Mokadem, A. An experimental investigation of the formability of low carbon steel tailor-welded blanks of different thickness ratios. Int. J. Adv. Manuf. Technol. 2016, 88, 1459-1473. [CrossRef]

33. Avramovic-Cingara, G.; Saleh, C.; Jain, M.; Wilkinson, D. Void Nucleation and Growth in Dual-Phase Steel 600 during Uniaxial Tensile Testing. Met. Mater. Trans. A 2009, 40, 3117-3127. [CrossRef]

(C) 2020 by the authors. Licensee MDPI, Basel, Switzerland. This article is an open access article distributed under the terms and conditions of the Creative Commons Attribution (CC BY) license (http://creativecommons.org/licenses/by/4.0/). 